\title{
Using Filon Fourier Spectral Analysis Technique for Filtering of Aeromagnetic Data and Outlining Subsurface Structures of Helma-Madrakah Area, Kingdom of Saudi Arabia
}

\author{
Hamdy I.E. Hassanein \\ Geophysics Department, Faculty of Earth Sciences, \\ King Abdulaziz University, Jeddah, Kingdom of Saudi Arabia \\ Received: 23/9/2000Ｒevised: 9/5/2001 Accepted: 5/11/2001
}

Abstract. The Helma-Madrakah area lies in the northern part of the Makkah quadrangle located in the southern part of the Hijaz region, western Saudi Arabia. The area is bounded by longitudes $39^{\circ} 30^{\prime} \mathrm{N}$ and $39^{\circ} 54^{\prime} \mathrm{E}$ and latitudes $21^{\circ} 45^{\prime} \mathrm{N}$ and $22^{\circ} 00^{\prime} \mathrm{N}$; i.e., north of Makkah AlMukarramah and north-east of Jeddah.

The present study deals with the interpretation of aeromagnetic data, which conducted by Aero-Service Corporation in the period 1965-1966 to depict subsurface regional and residual subsurface structural features. The Filon Fourier spectral analysis technique is used to determine average depths to the causative bodies $(6.0,1.2$ and $0.7 \mathrm{~km})$ of regional and residual anomalies. Special windows are designed and used to calculate the regional and residual components at each point along several profiles. Accordingly, the regional and residual magnetic maps of the area under study were produced.

The regional magnetic contour map indicates the rocks in the eastern part of the area to be more acidic than these in the western part.

The residual magnetic contour maps, on the other hand, show a number of higher frequency dipole magnetic anomalies. This reveals that the near surface rocks contain a certain amount of magnetic minerals. Therefore, the locations of these anomalies are considered very important for mineral exploration.

A basement structural map constructed using regional and residual magnetic maps as well as the geological map of the area, shows the area to be dissected by a set of N-S, NNW and NNE strctural trends. 


\section{Introduction}

Helma-Madrakah area is located in the southern part of the Hijaz region, western Saudi Arabia. The present study area is bounded by latitudes $21^{\circ} 45^{\prime} \mathrm{N}$ and $22^{\circ} 00^{\prime} \mathrm{N}$, and longitudes $39^{\circ} 30^{\prime} \mathrm{E}$ and $39^{\circ} 54^{\prime} \mathrm{E}$ (Fig. 1). It lies to the north of Makkah Al-Mukarramah and to the north-east of Jeddah and is located on the rifted western margin of the Arabian Shield.

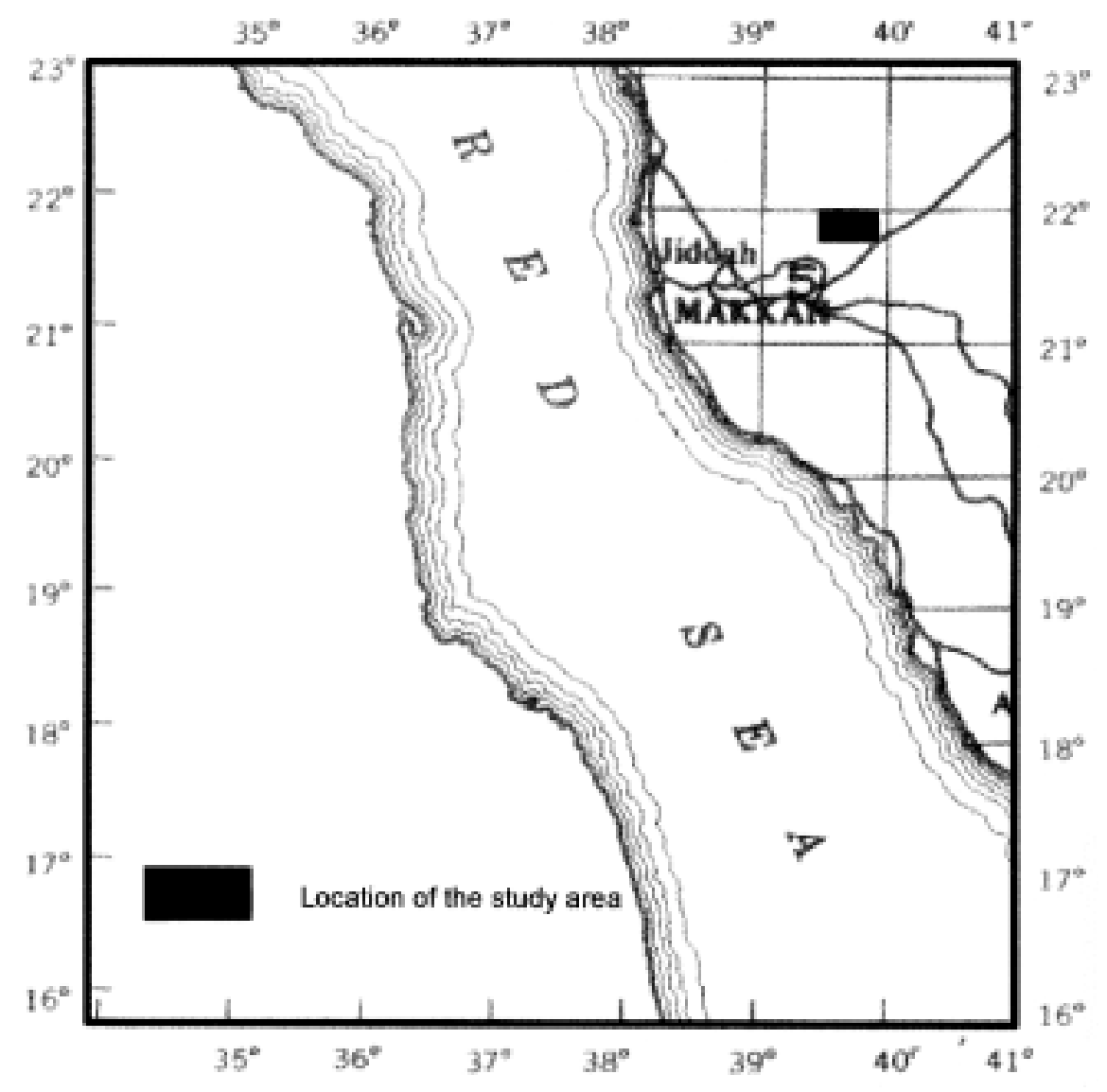

FIG. 1. Location of the study area.

Precambrian igneous and metamorphic rocks cover the main part of the area under study, as a part of the Arabian Shield basement complex. Some parts of the area are covered by sedimentary rock formation (Brown et al., 1963, AlShanti, 1966 and Hashem, 1971).

Large batholiths and discrete plutons of Precambrian age mainly occupy the area under study. All batholiths contain synclinal keels, rafts, roof pendants, and screens of late Precambrian layered rocks that are predominantly meta- 
morphosed lavas and volcaniclastic rocks ranging from basalt to rhyolites. Tilted and faulted Tertiary clastic sedimentary rocks are contained in the parallel depositional troughs. Flat-laying Tertiary basalts of Harrat Rahat and its erosional remnants cap the Tertiary deposits and Precambrian rocks (Moore and El-Rehaili, 1989).

In addition, the Makkah quadrangle is dominated by two main structural trends, north-northeast to northeast and north-northwest, that shows up well on satellite images. The trends east of north related to several Precambrian phases of deformation, and those west of north reflect faulting, fracturing and shearing associated with Tertiary rifting of the Red Sea. Structures with easterly and north westerly trends are less common and are probably of Precambrian age (Moore and El-Rehaili, 1989).

Figure 2 shows the geologic map of the area under study. This map reveals that the eastern part of the area is mainly characterized by acidic basement rocks represented by the Hishash complex and Shiwan complex. The western part of the area is mainly covered by Cenozoic sedimentary formations, as well as by basaltic flows of Harrat Al Jabiyrah, Harrat Al-Musllimiya and Harrat AlUbaysia.

The present geophysical study is based on the aeromagnetic data obtained by digitization of the total intensity aeromagnetic contour map of the area under study. This map is included in a sheet coded $23 \mathrm{DD}$, which is one of a group of sheets produced in the period 1965-1966 by Aero-Service Corporation. The airborne survey was conducted with $300 \mathrm{~m}$ of terrain clearance and flight line spacing of $800 \mathrm{~m}$. The main magnetic inclination in the area is $28^{\circ}$ and the declination is $00^{\circ} 58^{\prime}$ (Aero-Service, 1965-1966). The aeromagnetic map is digitized along each flight line, and the data obtained are presented as a new aeromagnetic contour map (Fig. 3).

The present study deals with the use of and correlation between the resulted data and the geology of the area to infer the relation between the surface structural geology of the area and the subsurface structures.

Filon Fourier spectral analysis is used to determine the average depths to the deep-seated and of the shallow structures.

\section{Analysis of Aeromagnetic Data}

\section{Frequency Analysis}

There are many techniques to separate regional and residual magnetic component maps from a total intensity map. Spectral analysis is one of these techniques, which is based theoretically on a Fast Fourier transform. Sadek (1978) 


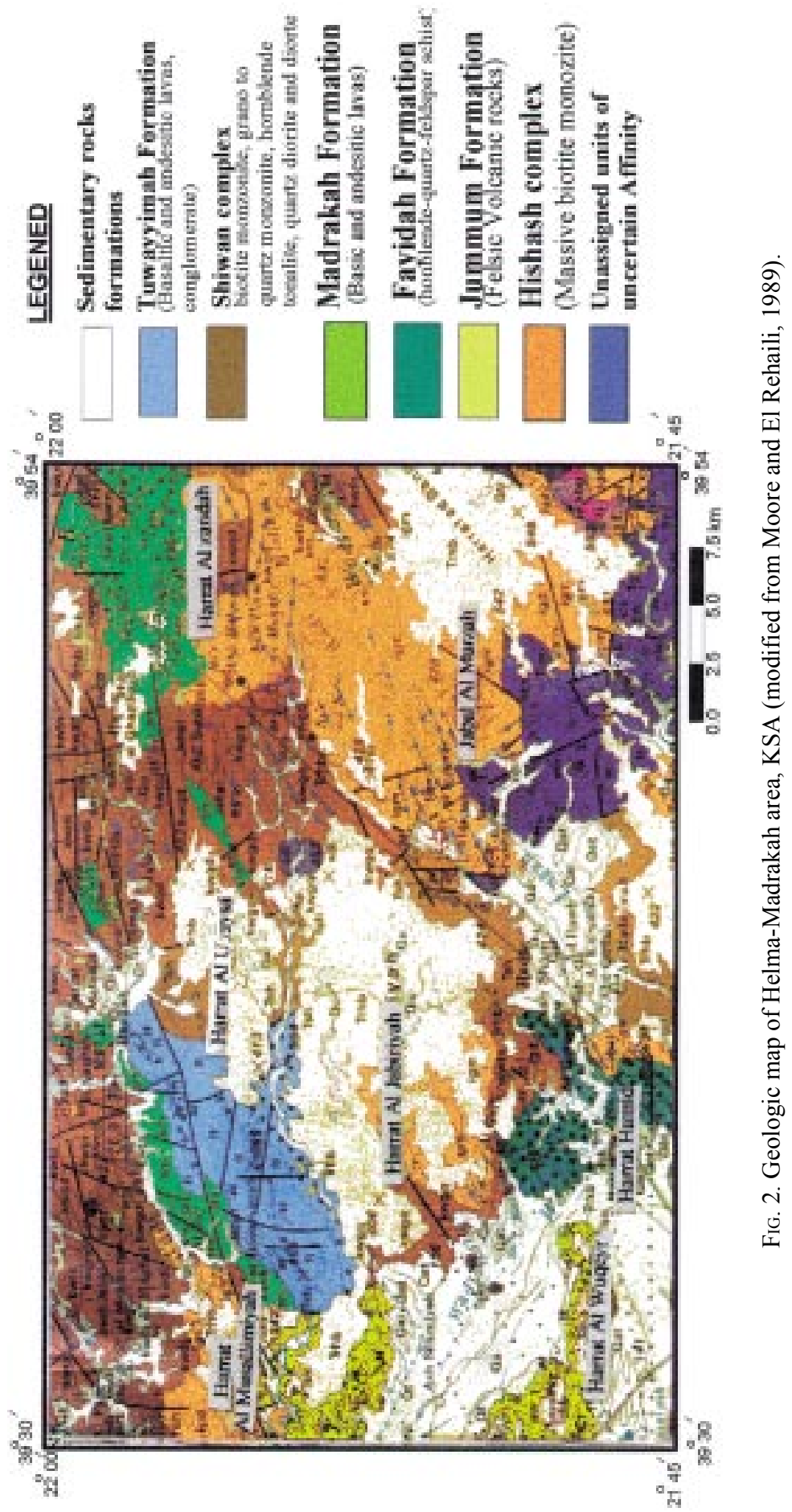




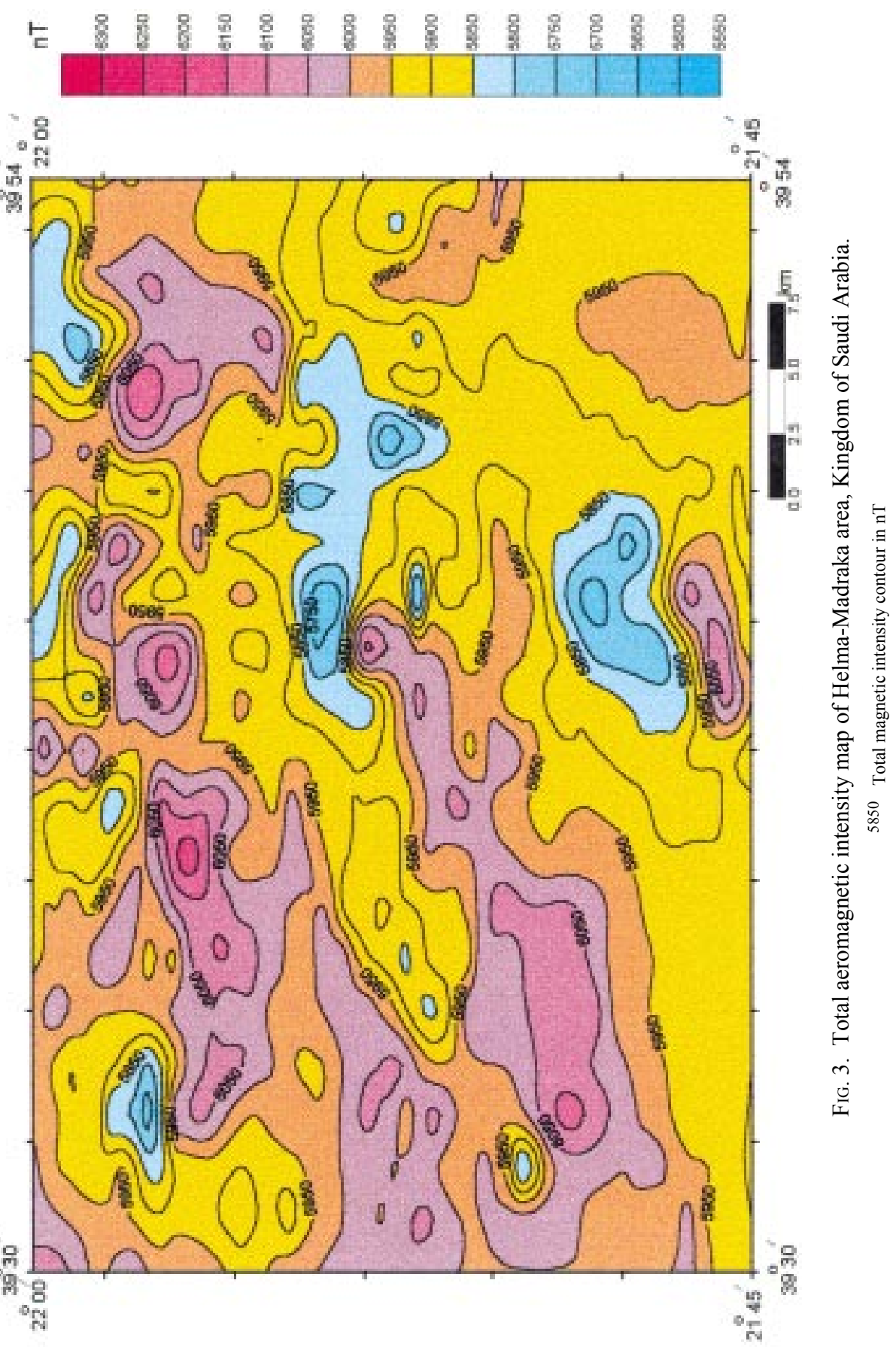


made a comparison between Fast Fourier transform and Filon Fourier transform and concluded that the Filon transform yields better identification of the energy in high frequency band and enables better resolution of the slopes in this band.

In the present study, the magnetic data were extracted along flight lines as profiles from the aeromagnetic map. The spacing between the flight lines was wider than the interval between the digitized data points along each profile. Therefore, frequency analysis along the profiles is most appropriate since it provides better resolution of shallow sources (Spector and Paker, 1979; Sadek et al., 1978 and Sadek, 1988).

The method was applied to digitized magnetic data, in profile form, to obtain the average depth to the subsurface geological sources and to obtain the differential magnetic response of each source ensemble that lying at a certain depth.

The aeromagnetic data along each profile, regarded as a set of equally spaced potential intensity data, were transformed into the frequency domain using the Fourier transformation. The Fourier transform integral of the function is expressed as

$$
F(q)=\int_{-\infty}^{\infty} F(x) \cdot e^{-i q x} d x
$$

where

$F(\mathrm{x})=$ the value of the function at a point $x$, and

$F(q)=$ is the transform at a wave number $q$

Parker (1979) suggested the multiplication of the field intensity by a Hanning weighting function $(G(X))$ that gradually smoothes the intensity to zero at the end points.

The Fourier Transform of equally spaced data along each profile can be approximated by the formula

$$
\bar{T}(q)=\int_{-L}^{L} T_{1}(x) e^{-i q x} d x,
$$

where

$T(q)=$ The Fourier transform

$$
T_{1}(q)=T(x) \cdot G(x)
$$

where

$$
T(x)=\text { the field value at a point }(x) \text {, and } G(x)=\text { Hanning Window }
$$




$$
G(x)=0.5\left[1+\cos \left(2 \pi \cdot x / L_{x}\right)\right]
$$

Using Euler's theorem,

$$
e^{-i(q x)}=\cos (q x)-i \sin (q x)
$$

Then Equation (2) can be rewritten in the form

$$
T(q)=K_{c}-i K_{s}
$$

where

$$
K_{C}=\int_{-L}^{L} T_{1}(x) \cdot \cos (q x) d x, \text { and } K_{S}=\int_{-L}^{L} T_{1}(x) \cdot \sin (q x) d x
$$

The transform can be calculated by computing the numerical value of the two trigonometric cosine and sine integrals $\left(K_{c}\right.$ and $\left.K_{s}\right)$. Filon modified Simpson's Rule and developed a more precise solution for the trigonometric functions. The solution involves fitting of $T$ in successive intervals of $x_{j-1}, x_{j+1}$ with parabolic arcs (Tranter, 1962). Using Filon's solutions, if the quantities $\alpha, \beta$ and $\gamma$ are defined as

$$
\begin{aligned}
& P^{3} \alpha=P^{2}+(P \cdot \sin (P) \cdot \cos (P))-2 \cdot \sin ^{2}(P) \\
& P^{3} \beta=2 \cdot\left(P\left(1+\cos ^{2}(P)\right) 2 \cdot \sin (P) \cdot \cos (P)\right. \\
& P^{3} \gamma=4 \cdot(\sin (P) \cdot \cos (P))
\end{aligned}
$$

where

$$
P=q \cdot \Delta x
$$

Then the numerical solutions of cosine and sine integrals are given as

$$
K_{C}(q)=\Delta x\left(\left[\left(T_{1}\left(N_{x}\right)-T_{1}(1)\right] \alpha \sin (q L)+\beta R_{1}+\gamma R_{2}\right)\right.
$$

and

$$
K_{S}(q)=\Delta x\left(-\left[\left(T_{1}\left(N_{x}\right)-T_{1}(1)\right] \alpha \cos (q L)+\beta I_{1}+\gamma I_{2}\right)\right.
$$

letting

$$
N_{1}=\left(N_{x}-3\right) / 2 \quad \text { and } \quad N_{2}=\left(N_{x}-1\right) / 2 \text {, }
$$

Then, the quantities $R_{1}, R_{2}, I_{1}$ and $I_{2}$ are given by

$$
R_{1}=\sum_{j=1}^{N_{1}} T_{1}(2 j+1) \cdot \cos [q(2 j x-L)]+0.5\left[T_{1}\left(N_{x}\right) \pm T_{1}(1)\right] \cos (q L)
$$




$$
\begin{aligned}
& R_{2}=\sum_{j=1}^{N_{1}} T_{1}(2 j) \cdot \cos [q \cdot(\Delta x(2 j-I)-I] \\
& I_{1}=\sum_{j=1}^{N_{1}} T_{1}(2 j+1) \cdot \sin [q(2 j x-L)]+0.5\left[T_{1}\left(N_{x}\right) \pm T_{1}(1)\right] \sin (q L) \\
& I_{2}=\sum_{j=1}^{N_{1}} T_{1}(2 j) \cdot \sin [q \cdot(\Delta x(2 j-I)-I)]
\end{aligned}
$$

Filon showed that at zero frequency, $q=p=0, \alpha=0, \beta=2 / 3$ and $\gamma=3 / 4$. Then, the value of $K s(q)=0$ and

$$
K_{c}(q)=\Delta x / 3\left(2 \cdot \sum_{j=1}^{N_{1}} T_{1}(2 j+1)+4 \sum_{j=1}^{N_{2}} T_{1}(2 j)+\left[T_{1}\left(N_{x}\right)+T_{1}(1)\right]\right)
$$

Substitution of the quantities $R_{1}, R_{2}, I_{1}$ and $I_{2}$ into Equation (10) and (11) enables the calculation of the real and imaginary parts of the transform in Equation (6). The value of the transform is then computed at the corresponding frequency $(f)$ ranging from zero to $f_{N}$ using a frequency interval of $\Delta f$. To study the behavior of the transform, it is preferable to calculate either the amplitude or the energy spectrum $(A(f)$ or $E(f)$, respectively). The amplitude and energy spectra are given as

$$
A(f)=\sqrt{K_{C}^{2}}+K_{S}^{2}
$$

From transform and plot any of them against the frequency the amplitude and energy are given as:

$$
E(f)=T(f) \cdot T^{*}(f)=K_{C}^{2}+K_{S}^{2},
$$

where $T^{*}(f)$ is the complex conjugate of the transform.

Spector and Grant (1970) demonstrate that the contributions from the depths $(H)$, widths $(S)$ and thicknesses $(C)$ of a source ensemble can affect the shape of the energy spectrum decay curve. In the case of a profile form it can be written as

$$
\ln (E(q))=\ln (H(h, q)+\ln (S(a, q))+\ln (C(t, \varphi, q))+\text { constant } t,
$$

where $(h),(a)$ and $(t)$ are the average depth, half width and thickness of the source ensemble, respectively. The effect of each factor has been discussed in many previous studies; however, a comprehensive study of these factors was given for the 3 and 2-d models by Sadek et al. (1984). 
The depth to the source ensemble $H(h, q)$ is the main factor, which controls the shape of the energy spectrum decay curve. It is expressed as

$$
H(h, q)=e^{-2 h q}
$$

The decay slopes of the curve at lower and higher frequencies describe depths to deeper and shallower sources, respectively. The slope of a line fitted to any linear segment of the curve can be used to compute either the depth to the causative source or the mean depth to a corresponding group of sources having comparable depths it is clear from Equation (19) that if $S=C=1$ (2a> $h$ and $t>h$ ), then the equation will be reduced to

$$
\ln (E q)=\ln (H(h, q))+\text { constant } t
$$

But from Equation (20) is clear from Equation (19) that if $S=C=1(2 a>h$ and $t>h)$, then the equation will be reduced to

$$
\ln H(h, q)=-2 h q
$$

hence the depth to the top of the source $(h)$ can be computed from the slope as follows

$$
h=- \text { slope } / 2 \text { if }(E) \quad \text { is plotted against }(q)
$$

or

$$
h=- \text { slope } \quad \text { if }(E) \text { is plotted against }(f)
$$

where

$$
\text { slope }=\ln (E(q) / q) \text { and } q=2 \cdot \pi \cdot f
$$

In order to achieve the purpose of this study, the aeromagnetic data are analyzed by using the Filon Fourier spectral analysis to determine the filtering parameters. These parameters are the average depth of deep-seated geological structures along all profiles of the area under study, and the average depth of near surface geological structures, the range of frequency of the regional and near surface components gained from aeromagnetic data. The frequency analysis curve (Fig. 4) shows that there are two distinctive linear segments along the curve. One segment at low-frequency (long wavelength) end to a spectrum with steep slope in power, which is termed regional, this is due to deep and/or broad sources. At high frequencies (short wave length), the residual part has a flatter slope and is due to relatively shallow sources. Spector and Grant (1970) showed that a single straight line fitted to a part of the spectrum corresponds to a single depth. The depth estimation of the magnetic anomalies of both regional and residual yields values of 5.97 and $1.18 \mathrm{~km}$, respectively. Besides, the frequency analysis curve shows another linear segment corresponding to higher frequencies. This segment indicates more shallow seated magnetic anomalies $0.7 \mathrm{~km}$ (Fig. 4) 


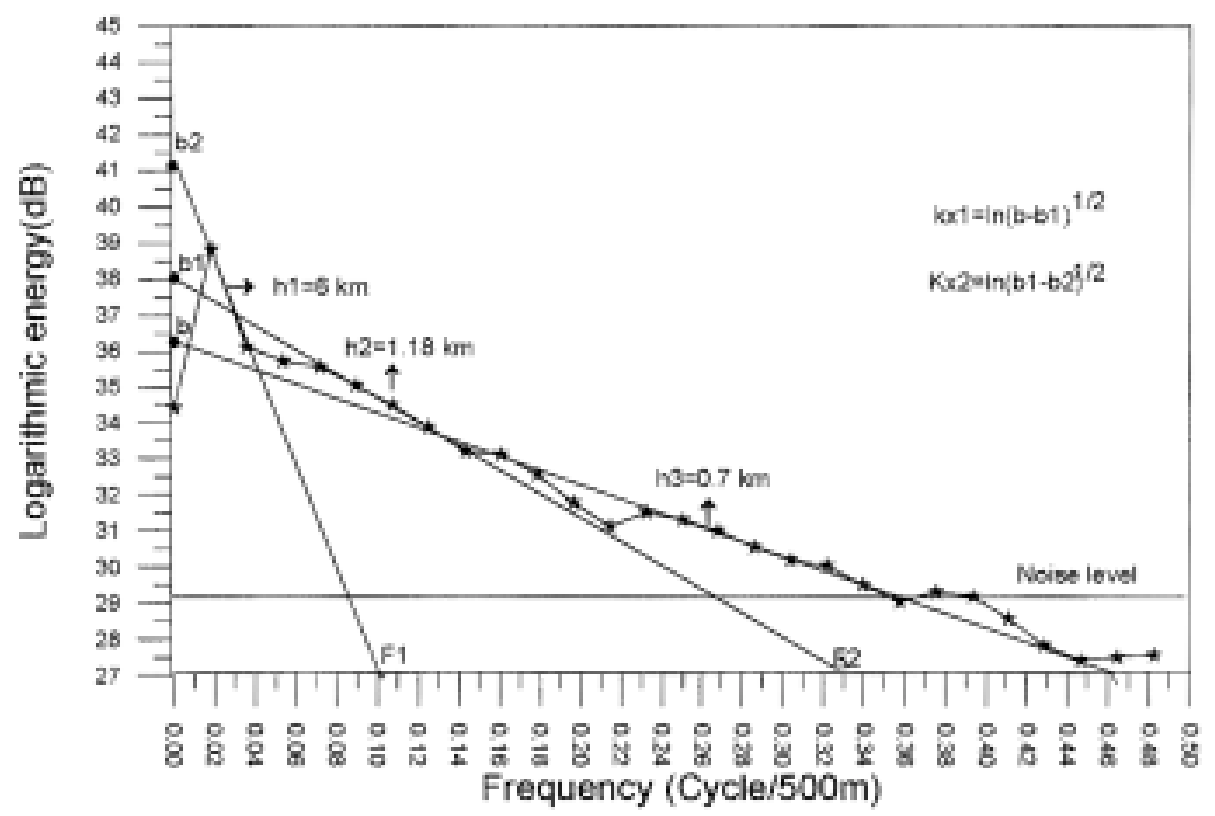

FIG. 4. Frequency analysis curve of total aeromagnetic intensity data, Helma-Madrakah, Kingdom of Saudi Arabia.

\section{Filtering (Regional and Residual Separation)}

An important technique in geophysical exploration is residual mapping in which local anomalies are separated from the regional trends. According to Burger (1992), the definition of a residual depends on the exploration target.

Generally, in the aeromagnetic maps of a limited area, the regional trend may appear in uniform variation represented by parallel, evenly spaced, contours. A local anomaly, which ordinary would be indicated by closed contours, appears as "nose" on the regional anomaly field (Sharma, 1976). These local or residual anomalies, caused by local geologic structures, can be separated from the measured field by using either the graphical or analytical methods.

Spector and Parker (1979) discussed the different operators for the filtering of 3-D aeromagnetic data using the Fourier Transform. The filters are used to carry out matched filtering, continuation, magnetic pole reduction and pseudogravity inversion. Some of these operators can be used for the profile (2-D) filtering. The

$$
T_{f}(q)=T(q) \cdot W(q)
$$

where

$$
T f(q)=\text { The filtered transform }
$$


steps of the filtering operation are

$$
\begin{aligned}
& W(q)=1+(b / B) \cdot e^{(H-h) q-1} \\
& W(q)=\text { the window filter }
\end{aligned}
$$

where $b$ and $B$ are the amplitude of deep and shallow sources (Fig. 4).

To perform the filtrating, the step by step procedure was employed as follows:

1 - The energy decay curve was carefully examined to recognize the following parameters:

a - The noise level, at high frequency end, which results from the round off errors in the magnetic values and from the spacing interval. This level is considered as the base of the curve when the matched filtering parameters are investigated.

$\mathrm{b}$ - A line fitted to each segment was drawn and the slope of this lines was determined to be utilized in depth determination according to Equation (22).

$c$ - The fitted lines were extended to intersect the energy axis at the points from which the values $k x$ and $b / B$ were computed and utilized in matched filtering.

$\mathrm{d}$ - The frequency intervals of each segment were determined from the frequency axis, where the low frequency interval lies between frequency 0 and $f_{1}$, while the intermediate and high frequency intervals are bounded by $f_{1}, f_{2}$ and $f_{2}, f_{3}$, respectively (Fig. 4).

2 - The parameters $k x_{1}, k x_{2}, h_{1}, h_{2}, h_{3}, f_{1}$ and $f_{2}$ (Fig. 4) were used to compute the window filters, which separate the magnetic response of each source ensemble.

The filtering process was executed by a computer program, designed by Sadek et al .(1984), which was employed as follows:

1 - The regional part is considered to be the combined effect of deep and intermediate sources. Therefore, the first filter is applied to compute their response.

2 - This component is subtracted from the total intensity values to obtain the response of shallower sources.

3 - The second filter is used to the computed part in step (1), hence the response of the intermediate sources can be obtained by subtracting the filtered component from the computed part in step (1).

Figure 5 explains the whole procedure applied to one of total aeromagnetic intensity profiles (profile no. 10), as example. 

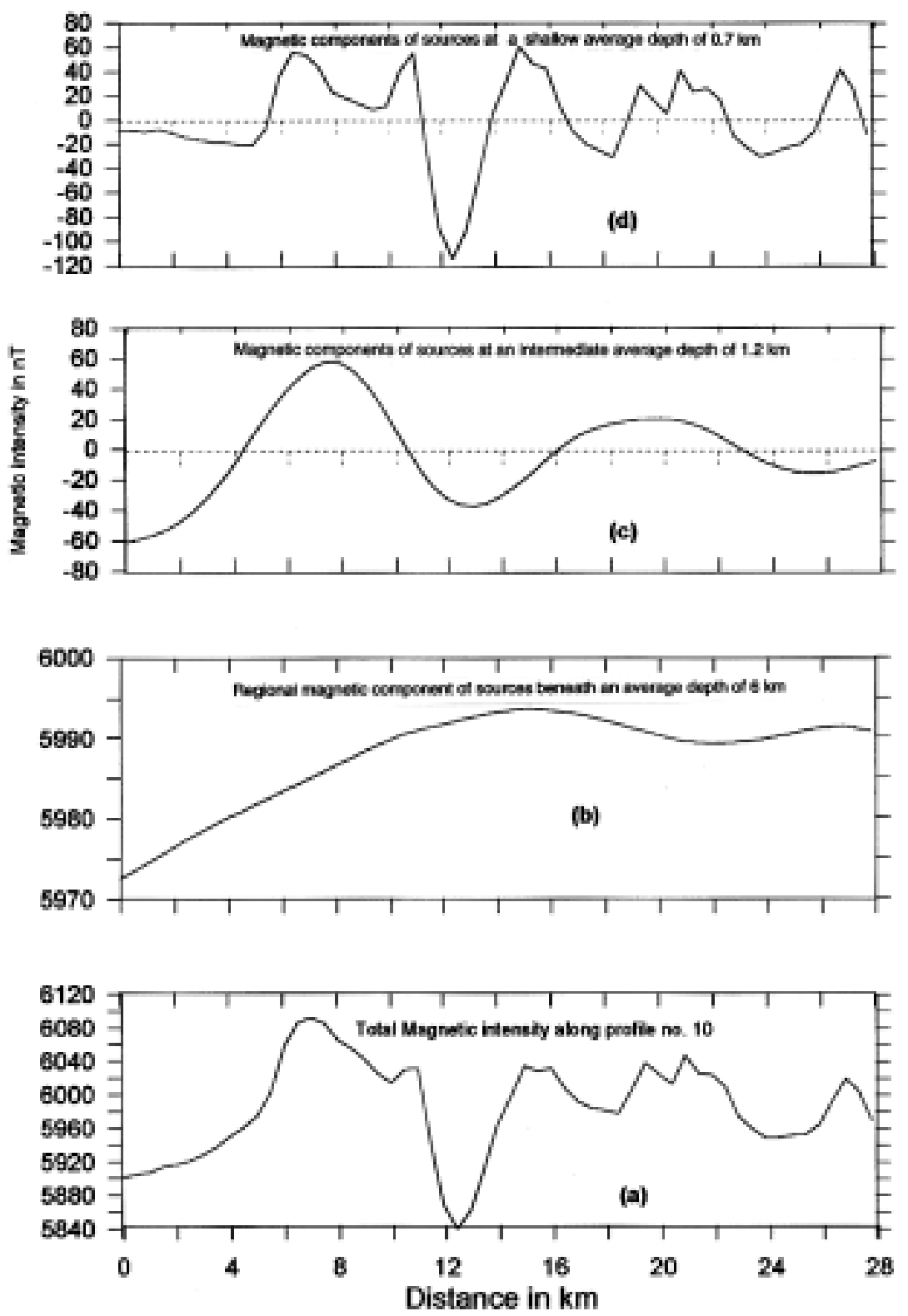

FIG. 5. Total magnetic intensity curve of the digitized profile no. 10(a), (b), (c) and (d) are the three magnetic component curves (regional, intermediate, and near surface, respectively) obtained by filtering the data in (a). 
As a result of applying this technique, the total intensity aeromagnetic map data were separated into three maps. The first map (Fig. 6) is the regional field at an average depth of $5.97 \mathrm{~km}$. The other two maps are considered as two residual maps, at depths 1.18 and 0.7 (Fig. $7 \& 8$, respectively). These maps are more amenable to interpretation.

\section{Interpretation of Aeromagnetic Survey Data}

The total-intensity aeromagnetic map (Fig. 3) shows that there are a number of different magnetic anomalies with different amplitudes and frequencies. The amplitudes range from 5600 and 6200nt after subtracting the base value. The spectral analysis using the Filon Fourier transform and filtering procedures resulted in one regional map and two residual maps. Each of these three maps has a different magnetic character, which can be used to detect the boundaries of the intra-structural features of the basement at corresponding average depths.

Consequently, the regional (Fig. 6) and the two residual magnetic maps (Fig. 7 and 8) classify and separate the anomalies of the total magnetic intensity map (Fig. 3) into low frequency anomalies which are related to deep-seated bodies and high frequency anomalies related to near-surface bodies. The residual magnetic component maps (Fig. 7 and 8) show a successive system of magnetic dipoles extending in the ENE-WSW direction. The calculated average depths of these anomalies are 1.17 and $0.7 \mathrm{~km}$, respectively. These may be due to a system of near surface structures aligned in this direction. The correlation between the locations of these anomalies and geologic map of the area (Fig. 2) show that the northern line of dipoles is related with a major fault extending in an WSWENE direction corresponding also with basaltic outcrops. Accordingly, there is a relation between the structural system and the basaltic flows in this part of the study area. Other magnetic dipoles are related with other geologic features. The regional magnetic component map (Fig. 6) shows that the area under study is divided into two parts with regard to the depth of the magnetic causative bodies. The eastern part with low frequency magnetic anomalies low amplitude, which refer to deep seated acidic rocks. In the other hand, the magnetic anomalies of the western part are characterized by high frequency and high magnetic amplitude, which related to near surface basic rocks. Between these two parts, there is a contact zone. Generally, these two divisions are correlated with the geological map (Fig. 2), where the eastern side is composed mainly of acidic rocks (Gabal Al Marzah), while the western part is composed of basaltic lava, which are mostly connected with the deep-seated basic materials.

The interpretation of the residual magnetic map (Fig. 8) shows a number of higher frequency magnetic anomalies. The anomalies are positive followed by negative values towards the north with the positive pole to the south. Further, 


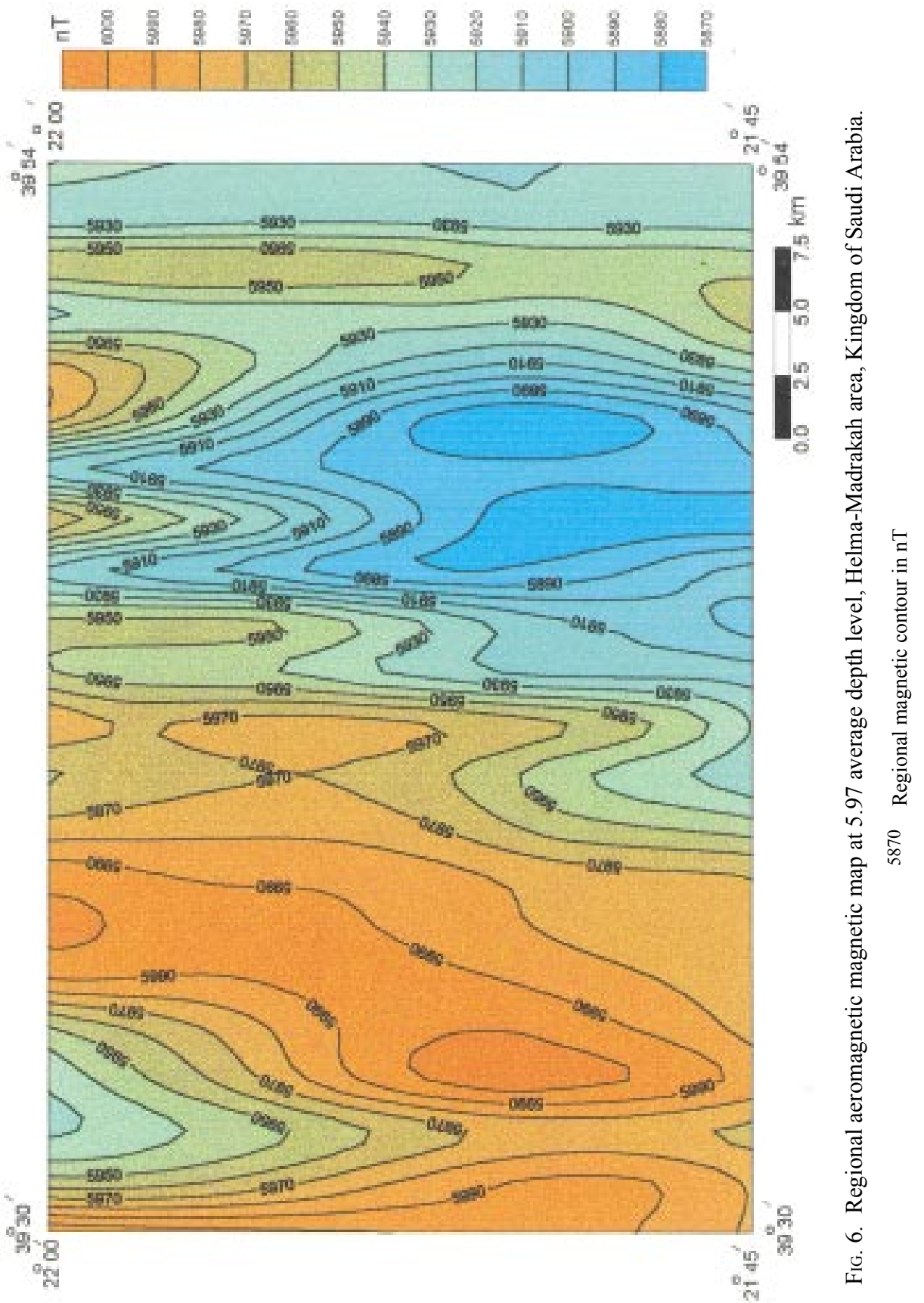




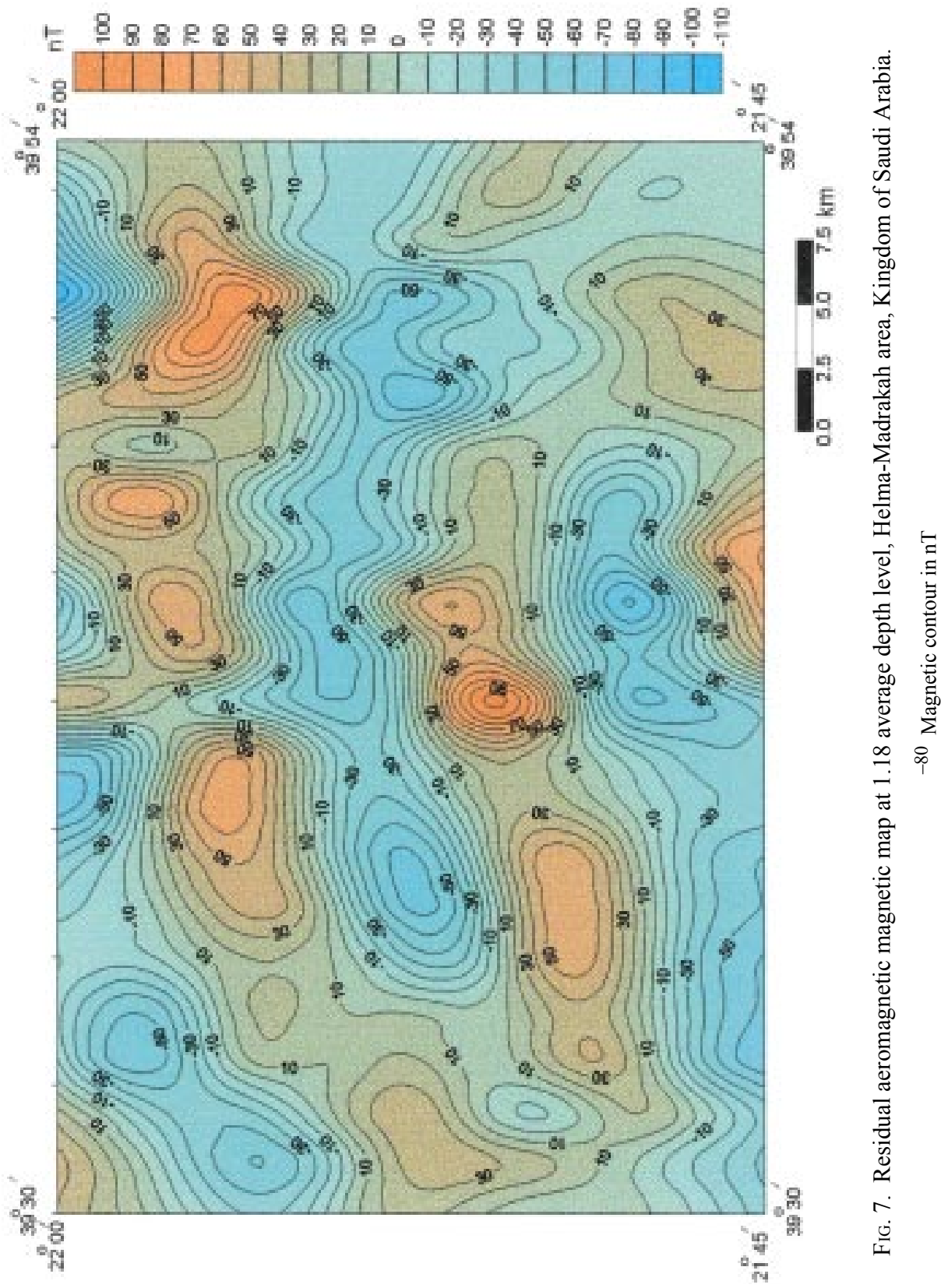




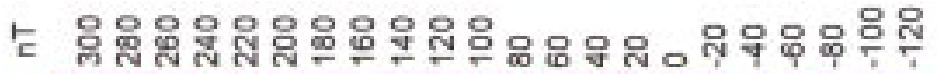

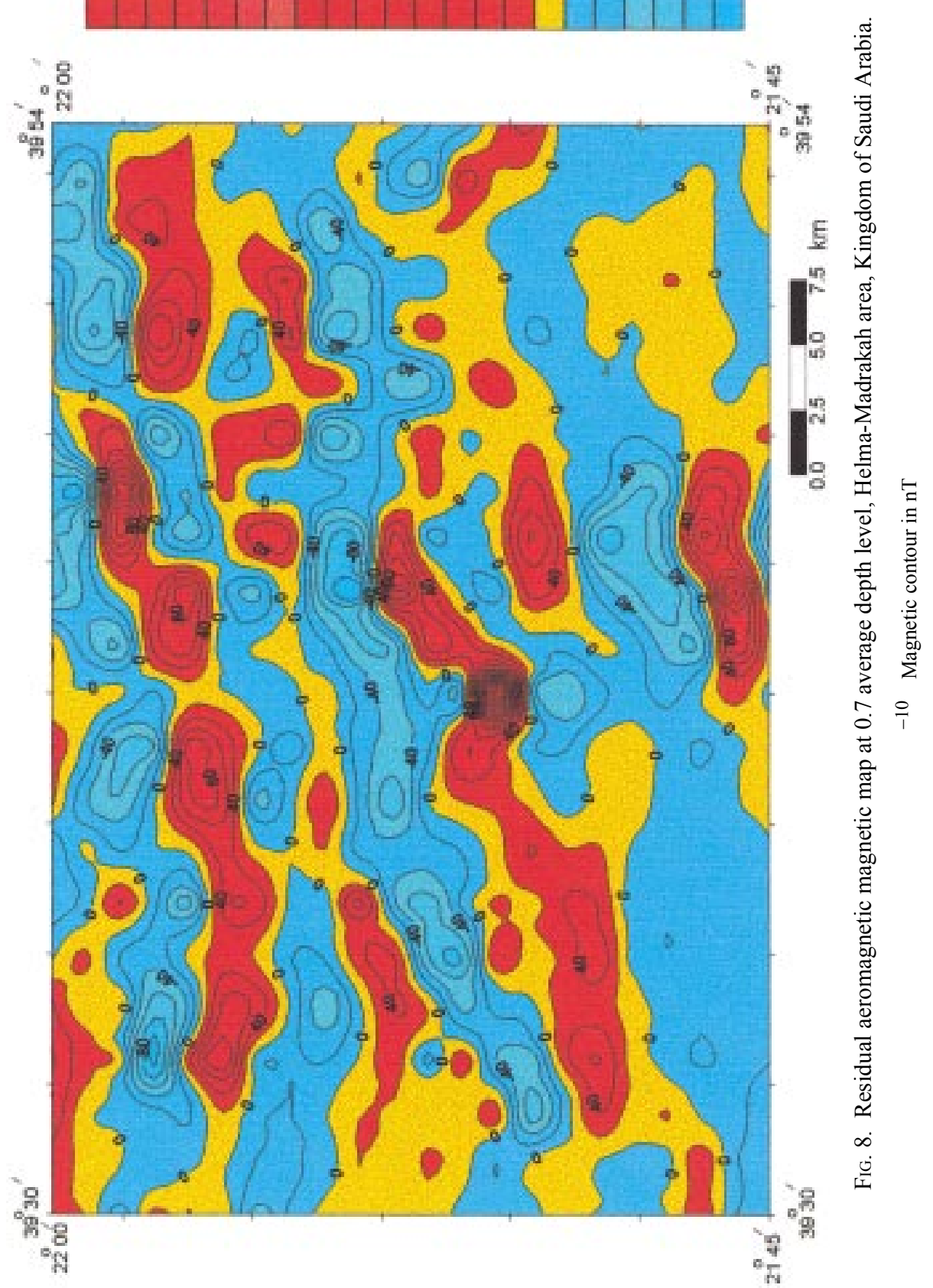


the positive amplitude pole of each anomaly is higher than the negative amplitude pole. The variations of the amplitude of anomalies indicate that these anomalies are due to occurrences of near surface rocks containing large amounts of magnetic minerals. Therefore, the locations of these anomalies are considered to be very important for mineral exploration.

Finally, the results of the interpretation are presented as a basement tectonic map (Fig. 9). This map shows the relation between the interpreted regional and residual structures. The correlation between the geological map of the area (Fig. 2) and the basement tectonic map (Fig. 9) indicates that NNW and NNE as regional trends and E-W residual structures control the geological units and their contacts in the area under study.

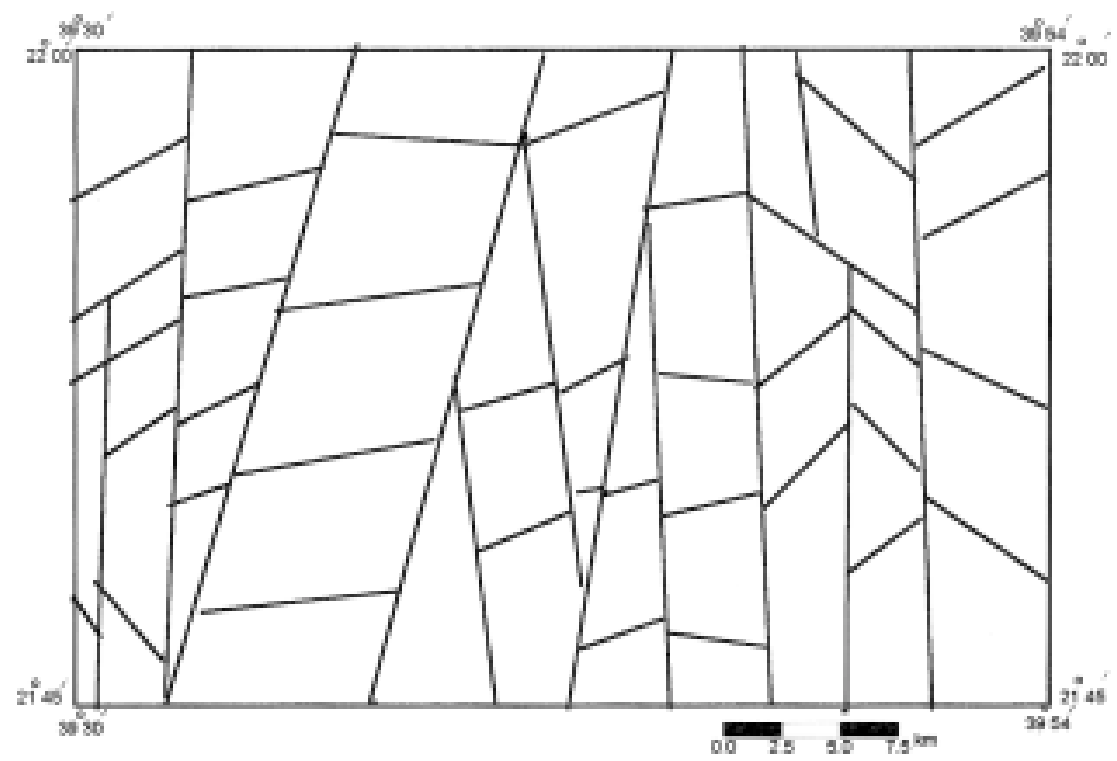

FIG. 9. Interpreted basement structures map of Helma-Madrakah area, Kingdom of Saudi Arabia.

- Interpreted structural lineaments.

\section{Conclusion}

The present study indicates that the application of the Filon Fourier Transform approach is an easy method for the interpretation of magnetic data and leads to a separation of the total magnetic data into regional and residual component maps. These maps are more easier to interpret than the original total magnetic intensity map. The following results were obtained for the study area:

1 - The frequency analysis showed that the sources of magnetic anomalies are located at three depth levels. These levels are 5.97, 1.18 and $0.7 \mathrm{~km}$. 
2 - The interpretation of the regional magnetic component map shows that the area under study is divided into two parts. The low magnetism, which characterized the eastern part of the area corresponds to the acidic rocks of Gabal Al Marza. In contrast, the western part is characterized by relatively higher magnetic intensity, which corresponds to near surface and more basic rocks.

3 - The interpretation of the residual magnetic maps shows a number of higher frequency magnetic dipole anomalies extending in an ENE-WSW trend. These anomalies may be due to occurrences near surface rocks containing larger amounts of magnetic minerals. Therefore, the locations of these anomalies are considered to be very important from the point of view of mineral exploration.

4 - The basement structural map of the area, constructed from the interpretation of the different magnetic maps, as well as from the geological map, is dissected by sets of N-S, NNW, and NNW structural trends.

\section{Acknowledgements}

The author is deeply grateful to Dr. Ahmed G. Hussain and Dr. Mohammed A. El Dafrawy for their advice and carefully reading the manuscript. Also it is appreciating the enthusiastic assistance of the colleagues of the department of Geophysics. Special thanks to Saudi Geological Survey for providing the airborne magnetic data.

\section{References}

Aero-Service Corporation, Hunting Geology and Geophysics Limited, and Lockwood Survey Corporation Limited. Under the Burau De Researches Geologiques Et Minieres, 19651966, Airborne Magnetometer-Scintilation Counter Survey Map, Scale 1:50,000, sheet DD.

Al-Shanti, A.M.S. (1966) Oolitic iron ore deposits in Wadi Fatima between Jeddah and Makkah, Saudi Arabian Directorate General of Mineral Resources Bulletin, 2: 51.

Brown, G.F., Jackson, R.O., Bogue, R.G. and MacLean, W.H. (1963) Geology of the Southern Hijaz quadrangle, Kingdom of Saudi Arabia: Saudi Arabian Directorate General of Mineral Resources Miscellaneous Geologic Investigations Map I-210A, 1:500,000 scale.

Burger, H.R. (1992) Exploration Geophysics of the Shallow Subsurface, Prentice and Hall, $489 \mathrm{p}$.

Hashem, W.B. (1971) The Geology and Geochemistry of the Precambrian Rocks in Wadi Fatima, Saudi Arabia, M.Sc., University of Bristol, United Kingdom.

Larken, G.P. (1936) Abu Hadid: Saudi Arabian Mining Syndicate, Open File Report 3/210/ $4050,1 \mathrm{p}$.

Moore, T.A. and El-Rehaili, M.H. (1989) Explanatory Notes to the Geological Map of the Makkah Quadrangle, sheet 21D, KSA.

Sadek, H.S. (1978) Relation between Geology and Aerial Radiometry of the Abu Swayel Area, Eastern Desert of Egypt, Correlated by Aeromagnetic Survey, Ph.D. Thesis, Cairo University, $284 \mathrm{p}$.

Sadek, H.S. (1988) Profile frequency analysis of potential field data using Filon Fourier transform, with Basic software, In: Andreas Vogel (ed), Geophysical Data Inversion Methods and Applications, Theory and Practice of Applied Geophysics: Model Optimization in Exploration Geophysics, vol. 2, Berlin, pp. 155-177. 
Sadek, H.S., Rashad, S.M. and Blank, H.R. (1984) Spectral Analysis of Aeromagnetic Profiles for Depth Estimation: Principles, Software and Practical Application, USGS-OF-04-27.

Sharma, P.V. (1976) Geophysical Methods in Geology, Elsevier Scientific Publishing Company, Amsterdam-Oxford-New York, $428 \mathrm{p}$.

Spector, A. and Grant, F.E. (1970) Statistical models for interpreting aeromagnetic data, Geophysics, 35: 293-302.

Spector, A. and Parker, W. (1979) Computer compilation and interpretation of geophysical data, In: Hood, P.J. (ed.), Geophysics and Geochemistry in the Search for Metallic Ores (Ed Mood P.), Geological Survey of Canada, Economic Geology Report 31: 527-544.

Tranter, C.J. (1962) Integral Transforms in Mathematical Physics, Methuem Monogram, 129 p. 


\section{استخدام تقنية تحليل فيلون - فورير الطيفي لترشيح المعطيات المغناطيسية الجوية وتحديد التراكيب تحت السطحية لمنطقة حلمة فيكة ومدركة ، المملكة العربية السعودية}

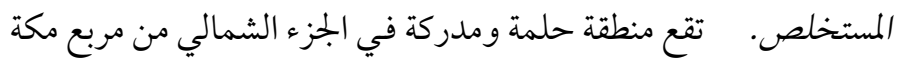

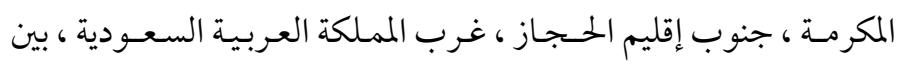

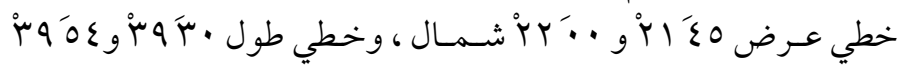

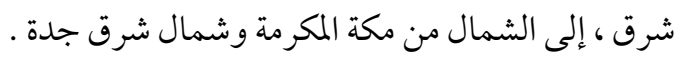

نفذت شركة إيروسيرفيس المساحة المغناطيسية الجلوية في خلال عامي

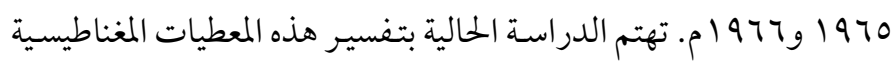

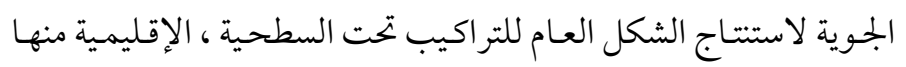

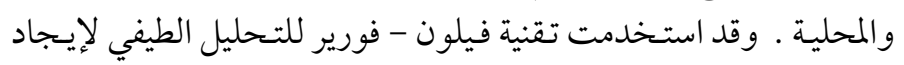

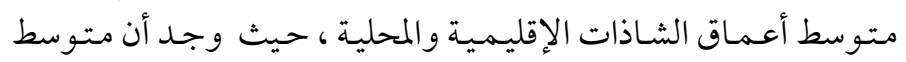

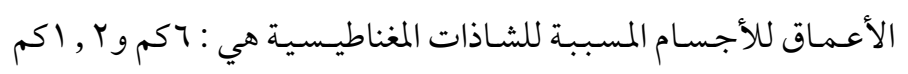

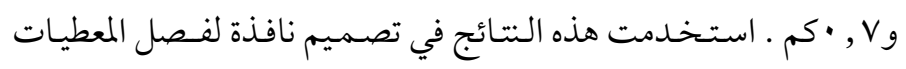

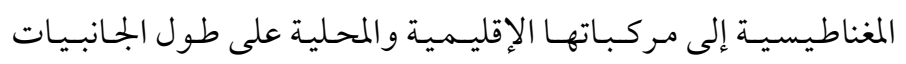

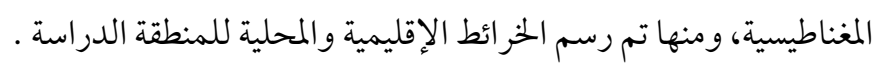
على ضوء ذلك ، اتضح من تفسير الخريطة الإقليمية أن الصخور تحت

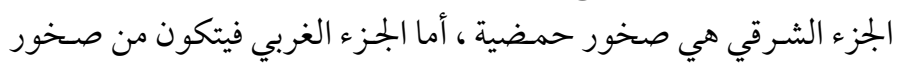

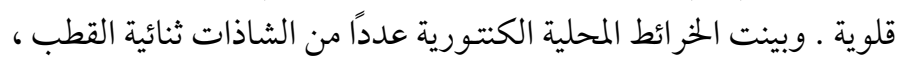

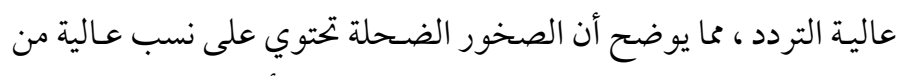

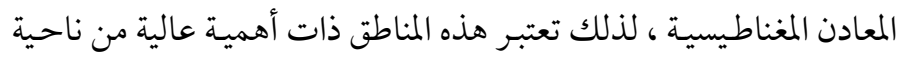

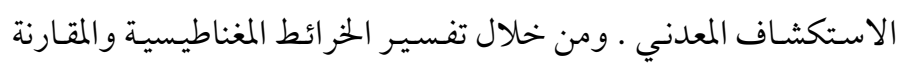


بالخريطة الجيـولوجيـة ، أمكن رسم خريطة تركيبية تحت سطحية ، وقد

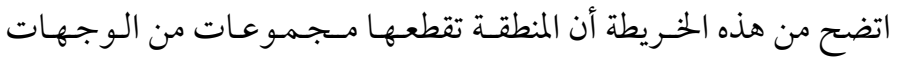

التركيبية في اتجاه شمال - جنوب وشمال شمال غرب وشمال وشمال شمال

شرق . 